УДК 616.12-008.331.1-085+615.252.349.7

DOI: 10.26435/UC.V0I3(36).530

О.С. Налётова, С.В. Титиевский, Е.Н. Налётова, С.В. Налётов, М.М. Алесинский, Т.А. Твердохлеб, Я.Ю. Галаева

ГОО ВПО «Донецкий национальный медицинский университет имени М. Горького», Донецк

\title{
УРОВЕНЬ ИСХОДНОГО СИСТОЛИЧЕСКОГО АРТЕРИАЛЬНОГО ДАВЛЕНИЯ, КАК ФАКТОР ЭФФЕКТИВНОСТИ ЛЕЧЕНИЯ БОЛЬНЫХ ГИПЕРТОНИЧЕСКОЙ БОЛЕЗНЬЮ, СОЧЕТАННОЙ С РАССТРОЙСТВОМ АДАПТАЦИИ
}

В настоящее время депрессия рассматривается как независимый фактор риска в патогенетической цепи сердечно-сосудистых заболеваний (СС3), а не как вторичная эмоциональная реакция на заболевание $[1,2,9]$. Некоторые авторы акцентируют внимание на влиянии хронического психического стресса на формирование дисфункции эндотелия (ДЭ) и процессы ремоделирования сосудов [3, 7, 8]. Как известно, ДЭ и, обусловленное ею уменьшение синтеза оксида азота (NO), является одним из главнейших патогенетических механизмов прогрессирования артериальной гипертензии (АГ) $[4,5]$. В этой связи весьма ценным является использование в качестве антигипертензивных лекарственных средств (АГЛС) препаратов, восстанавливающих одну из важнейших функций эндотелия сосудов - образование NO, обеспечивающего релаксацию сосудов и снижение артериального давления (АД).

Особый интерес представляет препарат L-аргинин, рекомендованный к использованию при гипертонической болезни (ГБ), но в практической медицине назначаемый довольно редко. L-аргинин является субстратом NO-синтаз в синтезе NO и повышает, таким образом, его образование клетками эндотелия сосудов $[4,6]$.

Ранее нами доказана эффективность и безопасность включения L-аргинина в дозе 750 мг 1 раз в сутки (в течение двух недель с двухнедельными перерывами) в составе стандартной антигипертензивной фармакотерапии у больных ГБ, сочетанной с расстройством адаптации на протяжении 24 недель [6].

\section{ЦЕЛЬ ИССЛЕДОВАНИЯ}

Оценить эффективность лечения больных ГБ II стадии, сочетанной с расстройством адаптации.

\section{МАТЕРИАЛ И МЕТОДЫ}

Материалом для проведения математического анализа послужила оценка результатов фармакотерапии больных ГБ II стадии, сочетанной с расстройством адаптации, проживающих в г. Донецк. В исследование было включено 216 человек, у которых на консультативном приёме врача-кардиолога был подтверждён диагноз ГБ ІІ стадии, а после тестирования по шкале Бека [4-6] и консультации врача-психиатра было установлено сопутствующее расстройство адаптации.

На поликлиническом приеме врач-кардиолог проводил анализ антигипертензивной фармакотерапии, назначенной пациентам на предыдущих этапах лечения (участковым врачом). В случае необходимости были внесены коррективы в лечение в соответствии с клиническим статусом больных.

Больные были распределены на 3 группы: пациенты 1-й группы (n=71) в дополнение к антигипертензивной терапии проводили сеансы аутотренинга. Схема лечения пациентов 2-й группы (n=72) была следующей: антигипертензивная терапия + аутотренинг + функциональная музыка, а 3-й группы (n=73): антигипертензивная терапия + аутотренинг + функциональная музыка + L-аргинин в дозе 0,75 один раз в сутки (по схеме: две недели приём препарата, две недели перерыв).

Для проведения анализа эффективности терапии больных ГБ II стадии, сочетанной с расстройством адаптации, был использован метод построения многофакторных математических моделей классификации в пакете статистиче-

(c) О.С. Налётова, С.В. Титиевский, Е.Н. Налётова, С.В. Налётов, М.М. Алесинский, Т.А. Твердохлеб, Я.Ю. Галаева, 2020

(c) Университетская Клиника, 2020 
ских программ MedicalStatistics [10]. В качестве оценки эффективности терапии был выбран показатель САД на 12-й неделе лечения. Терапевтический эффект считался достигнутым в случае, когда на 12-й неделе лечения значение этого показателя достигало значений <140 мм рт. ст., иначе считалось, что эффект терапии не достигнут.

Как факторные признаки модели были использованы показатели, определяющие состояние больного на момент начала лечения. Всего использовалось 20 показателей: пол, возраст, начальные уровни: САД, ДАД, депрессия по Шкале Бека (ШБ), жизненное истощение (MQ), комплаентность (SMG), нейротизм (EPI), экстраверсия/ интроверсия по (ЕРI), самочувствие, активность, настроение (САН), физическое функционирование, ролевое функционирование, обусловленное физическим состоянием, интенсивность боли, общее состояние здоровья, жизненная активность, социальное функционирование, ролевое функционирование, обусловленное эмоциональным состоянием , психическое здоровье по (SF-36). Как факторный признак использовался также вариант лечения: 1 вариант (антигипертензивная фармакотерапия + аутотренинг); 2 вариант (антигипертензивная фармакотерапия + аутотренинг + функциональная музыка); 3. (антигипертензивная фармакотерапия + аутотренинг + функциональная музыка + L-аргинин 0,75 в сутки, двухнедельными курсами).

Как результирующий признак прогнозировалась эффективность лечения (Y). В случае, когда эффект был достигнут, то $\mathrm{Y}=1$, иначе лечение считалось неэффективным: $\mathrm{Y}=0$.

Модель строилась по результатам лечения 216 больных, при этом к началу лечения САД у всех больных составляло >140 мм рт. ст.

Для оценки адекватности модели все случаи (с использованием генератора случайных чисел) были разделены на 2 множества: учебное (использовалось для построения модели) и тестовое (использовалось для проверки прогностической способности модели на новых данных) [10].

\section{РЕЗУЛЬТАТЫ И ОБСУЖДЕНИЕ}

На первом этапе проведения анализа была построена линейная модель классификации с использованием как факторных всех 21 признаков. После обучения модели были получены следующие результаты: для обучающего множества чувствительность модели составила 92,2 $1,7 \%$,

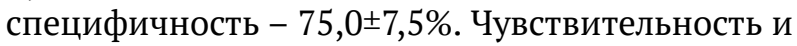
специфичность модели на учебном и тестовом множествах статистически значимо не различаются ( $\mathrm{p}=0,57$ и $\mathrm{p}=0,51$ соответственно, при срав- нении по критерию $\chi^{2}$ ), что свидетельствует об адекватности построенной модели.

Для выявления минимального набора факторных признаков, которые в наибольшей степени связаны с достижением эффекта был использован метод пошагового исключения. В результате анализа было отобрано 4 признака, которые в наибольшей степени определяют эффективность лечения: вариант лечения, уровень САД до лечения, начальный уровень депрессия по ШБ, начальный уровень нейротизма по ЕPI. На выделенном наборе факторных признаков была построена линейная модель прогнозирования эффективности лечения. На рисунке приведена кривая операционных характеристик построенной модели (ROC-кривая). Площадь под кривой составила $\mathrm{S}=0,94 \pm 0,04$ (статистически значимо p<0,001 отличается от 0,5).

Чувствительность модели на обучающем множестве составила $89,1 \pm 1,9 \%$, специфичность - 87,5 $\pm 6,8 \%$. На тестовом множестве верно классифицированы все случаи неэффективности ле-

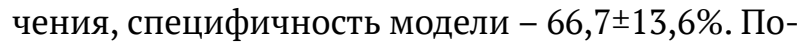
казатель отношения правдоподобия модели, $\mathrm{LR}+=7,1, \mathrm{LR}-=0,14$.

Чувствительность и специфичность построенной модели на обучающем и тестовом множествах статистически значимо не различаются ( $\mathrm{p}=0,94$ и $\mathrm{p}=0,32$ соответственно, при сравнении по критерию $\chi^{2}$ ), что свидетельствует о ее адекватности. При этом, уменьшение числа факторных признаков от 21 до 4 не привело к снижению прогностических способностей модели, чувствительность и специфичность модели, по-

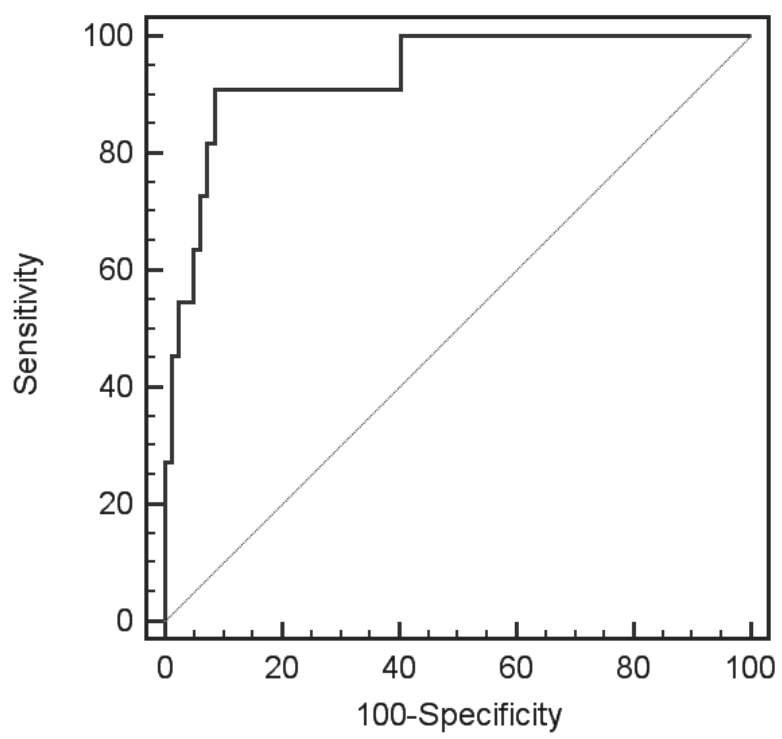

Рис. 1. ROC-кривая для четырехфакторной модели прогнозирования эффективности лечения по показателю САД 
Анализ влияния факторных признаков на прогноз эффективности лечения

Таблица. (логистическая регрессионная модель, построенная на наборе 4 наиболее значимых признаков)

\begin{tabular}{lccc}
\hline $\begin{array}{c}\text { Факторный } \\
\text { признак }\end{array}$ & $\begin{array}{c}\text { Значение коэффициента } \\
\text { прогнозирования, } \mathrm{b}^{ \pm m}\end{array}$ & $\begin{array}{c}\text { Уровень значимости отли- } \\
\text { чия коэффициента от 0 }\end{array}$ & $\begin{array}{c}\text { Оценка влияния признака } \\
\text { ОШ (95\%ДИ ОШ) }\end{array}$ \\
\hline \hline Вариант лечения & $-3,3 \pm 1,3$ & 0,01 & $25,0(15,0-50,0)$ \\
\hline САД & $-0,2 \pm 0,1$ & 0,03 & $1,25(1,4-1,1)$ \\
\hline Депрессия по ШБ & $-13,8 \pm 6,7$ & 0,04 & $1,7(2,0-1,4)$ \\
\hline
\end{tabular}

строенной на полном наборе признаков и модели, построенной на 4 признаках статистически значимо не отличаются (p>0,7).

Для выявления значимости влияния каждого из выделенных признаков был использован метод построения логистической регрессионной модели прогнозирования. Модель адекватна $\left(\chi^{2}=33,7, \mathrm{p}<0,0001\right)$. Результаты анализа коэффициентов модели приведены в таблице.

Проведенный анализ свидетельствует, что на статистически значимый $(\mathrm{p}=0,01)$ прогноз положительного результата влияет вариант лечения. Наиболее эффективно использование антигипертензивной фармакотерапии + аутотренинг + функциональная музыка + L-аргинин ( 0,75 в сутки, двухнедельными курсами); менее - антигипертензивная фармакотерапия + аутотренинг + функциональная музыка; наименее эффективная антигипертензивная фармакотерапия + аутотренинг отношение шансов (ОШ) 25,0 (95\% ДИ 15,0- 50,0).
Установлено, что вероятность положительного результата лечения связана с исходным уровнем САД_0. Так при увеличении значения этого показателя статистически значимо $(\mathrm{p}<0,03)$ снижаются шансы положительного прогноза лечения, ОШ = 1,25 (95\% ДИ 1,4-1,1) на каждый мм рт.ст. Обнаружено также влияние исходного значения уровня депрессии по ШБ_0, так при увеличении значения этого показателя статистически значимо $(\mathrm{p}<0,04)$ снижаются шансы положительного прогноза.

\section{В Ы В 0 Д Ы}

Использование у больных ГБ ІІ стадии, сочетанной с расстройством адаптации антигипертензивной фармакотерапии + аутотренинг + функциональная музыка + L-аргинин (по 0,75 в сутки, двухнедельными курсами) в сравнении с антигипертензивной фармакотерапией + ayтотренинг снижает риск неэффективности терапии по показателю САД $(\mathrm{p}=0,01)-$ ОШ $=25,0$ (95\% ДИ 15,0- 50,0).

О.С. Налётова, С.В. Титиевский, Е.Н. Налётова, С.В. Налётов, М.М. Алесинский, Т.А. Твердохлеб, Я.Ю. Галаева

ГОО ВПО «Донецкий национальный медицинский университет имени М. Горького», Донецк

\section{УРОВЕНЬ ИСХОДНОГО СИСТОЛИЧЕСКОГО АРТЕРИАЛЬНОГО ДАВЛЕНИЯ, КАК ФАКТОР ЭФФЕКТИВНОСТИ ЛЕЧЕНИЯ БОЛЬНЫХ ГИПЕРТОНИЧЕСКОЙ БОЛЕЗНЬЮ, СОЧЕТАННОЙ С РАССТРОЙСТВОМ АДАПТАЦИИ}

В статье представлены данные о математическом моделировании эффективности различных вариантов лечения (антигипертензивная терапия + aутотренинг; антигипертензивная терапия + аутотренинг + функциональная музыка; антигипертензивная терапия + аутотренинг + функциональная музыка + L-аргинин в дозе 0,75 один раз в сутки (по схеме: две недели приём препарата / две недели перерыв)) больных гипертонической болезнью II стадии, сочетанной с расстройством адаптации.

Установлено, что использование у больных ги- пертонической болезнью II стадии, сочетанной с расстройством адаптации антигипертензивной фармакотерапии + аутотренинг + функциональная музыка + L-аргинин (по 0,75 в сутки, двухнедельными курсами) в сравнении с антигипертензивной фармакотерапией + аутотренинг снижает риск неэффективности терапии по показателю САД (p=0,01) - ОШ = 25,0 (95\% ДИ 15,0- 50,0).

Ключевые слова: гипертоническая болезнь, расстройство адаптации, эффективность терапии, математическое прогнозирование. 


\section{O.S. Nalyotova, S.V. Titievsky, E.N. Nalyotova, S.V. Nalyotov, M.M. Alesinsky, T.A. Tverdokhleb, Y.J. Galaeva}

\section{SEI HPE «M. Gorky Donetsk National Medical University», Donetsk \\ THE LEVEL OF INITIAL SISTOLIC ARTERIAL PRESSURE AS A FACTOR OF EFFECTIVENESS OF TREATING PATIENTS WITH ARTERIAL HYPERTENSION COMBINED WITH ADJUSTMENT DISORDERS}

The article presents the information about the mathematical modeling of the effectiveness of various treatment options (antihypertensive therapy + auto-training; antihypertensive therapy + autotraining + functional music; antihypertensive therapy + autotraining + functional music $+\mathrm{L}$-arginine at a dose of 0,75 once a day (according to the scheme: two weeks taking the drug / two weeks break)) patients with arterial hypertension of stage II in a combination with an adjustment disorders.

It has been established that the use of antihyperten- sive pharmacotherapy + autotraining + functional music + L-arginine ( 0,75 per day, two-week courses) in comparison with antihypertensive pharmacotherapy + autotraining reduces in patients with arterial hypertension stage II combined with an adjustment disorders the risk of treatment inefficiency in terms of systolic blood pressure $(\mathrm{p}=$ 0,01) - OR = 25,0 (95\% CI 15,0- 50,0).

Key words: arterial hypertension, adjustment disorders, therapy effectiveness, mathematical prediction.

\section{ЛИТЕРАТУРА}

1. Агеев Ф.Т., Фофанова Т.В. Низкая приверженность лечению как причина резистентной артериальной гипертензии. Рефрактерная артериальная гипертония. Атмосфера. 2014; 28-32.

2. Алесинский М.М., Налётов С.В. Опыт работы в аптеке центра повышения комплаентности больных артериальной гипертензией, находящихся в условиях гуманитарной блокады Донбасса. Дальневосточный медицинский журнал. 2017; 1: 90-92.

3. Налётов С.В., Алесинский М.М., Налётова Е.Н. Зависимость уровня комплаентности от психотипа больных артериальной гипертензией, находящихся в условиях конфликта в Донбассе. Дальневосточный медицинский журнал. 2016; 4: 14-17.

4. Налётова О.С. Влияние комплексного лечения на функциональное состояния эндотелия сосудов у больных гипертонической болезнью с выявленной ситуационной депрессией, проживающих на Донбассе. Вестник волгоградского государственного медицинского университета. 2019; 1(69): 41-45.

5. Налётова О.С. Влияние комплексного лечения на покасатели суточного мониторирования артериального давления больных гипертонической болезнью с выявленной ситуационной депрессией. Университетская клиника. 2019; 2(31): 45-52.

6. Налётова О.С. Влияние психотерапевтического комплекса и L-аргинина в составе стандартной антигипертензивной фармакотерапии на качество жизни больных гипертонической болезнью, сочетанной с расстройством адаптации. Университетская клиника. 2019; 3(32): 13-19.

7. Налётова О.С. Комплексное лечение больных гипертонической болезнью с выявленной ситуационной депрессией, проживающих на территории Донбасса. Научные ведомости Белгородского государственного университета Медицина. Фармация. 2019; 1(42): 57-64.

8. Налётова О.С., Титиевский С.В., Белевцова Э.Л. Распространенность депрессии и жизненного истощения у больных гипертонической болезнью, проживающих на территории Донбасса. Курский научно-практический вестник «Человек и его здоровье». 2018; 3: 4-9.

9. Налетов А.В., Налётов С.В., Баринова А.С. Проблема комплаентности в современной гастроэнтерологии. Университетская клиника. 2017; 2(13): 213-218.

10. Лях Ю.Е. и др. Основы компьютерной биостатистики: анализ информации в биологии, медицине и фармации статистическим пакетом MedStat . Донецк: Папакица Е. К.; 2006. 214.

\section{REFERENCES}

1. Ageev F.T., Fofanova T.V. Nizkaya priverzhennost` lecheniyu kak prichina rezistentnoj arterial noj gipertenzii. Refrakternaya arterial naya gipertoniya. Atmosfera. 2014; 28-32 (in Russian).

2. Alesinskij M.M., Nalyotov S.V. Opy`t raboty`v apteke czentra povy`sheniya komplaentnosti bol`ny`kh arterial`noj gipertenziej, nakhodyashhikhsya $\mathrm{v}$ usloviyakh gumanitarnoj blokady`Donbassa. Dal 'nevostochny j mediczinskij zhurnal. 2017; 1: 90-92 (in Russian).

3. Nalyotov S.V., Alesinskij M.M., Nalyotova E.N. Zavisimost urovnya komplaentnosti ot psikhotipa bol`ny`kh arterial'noj gipertenziej, nakhodyashhikhsya $\mathrm{v}$ usloviyakh konflikta v Donbasse. Dal’nevostochny`j mediczinskij zhurnal. 2016; 4: 14-17 (in Russian).

4. Nalyotova O.S. Vliyanie kompleksnogo lecheniya na funkczional'noe sostoyaniya e`ndoteliya sosudov $u$ bol`ny`kh gipertonicheskoj bolezn `yu s vy`yavlennoj situaczionnoj depressiej, prozhivayushhikh na Donbasse. Vestnik volgogradskogo gosudarstvennogo mediczinskogo universiteta. 2019; 1(69): 41-45 (in Russian).

5. Nalyotova O.S. Vliyanie kompleksnogo lecheniya na pokasateli sutochnogo monitorirovaniya arterial nogo davleniya bol`ny`kh gipertonicheskoj bolezn`yu s vy`yavlennoj situaczionnoj depressiej. Universitetskaya klinika. 2019; 2(31): 45-52 (in Russian).

6. Nalyotova O.S. Vliyanie psikhoterapevticheskogo kompleksa i L-arginina v sostave standartnoj antigipertenzivnoj farmakoterapii na kachestvo zhizni bol 'ny kh gipertonicheskoj bolezn yu, sochetannoj s rasstrojstvom adaptaczii. Universitetskaya klinika. 2019; 3(32): 13-19 (in Russian).

7. Nalyotova O.S. Kompleksnoe lechenie bol`ny`kh gipertonicheskoj bolezn yu s vy`yavlennoj situaczionnoj depressiej, prozhivayushhikh na territorii Donbassa. Nauchny`e vedomosti Belgorodskogo gosudarstvennogo universiteta Mediczina. Farmacziya. 2019; 1(42): 57-64 (in Russian).

8. Nalyotova O.S., Titievskij S.V., Belevczova E`.L. Rasprostranennost ' depressii i zhiznennogo istoshheniya $u$ bol`ny`kh gipertonicheskoj bolezn `yu, prozhivayushhikh na territorii Donbassa. Kurskij nauchno-prakticheskij vestnik «Chelovek i ego zdorov`e». 2018; 3: 4-9 (in Russian).

9. Naletov A.V., Nalyotov S.V., Barinova A.S. Problema komplaentnosti v sovremennoj gastroe nterologii. Universitetskaya klinika. 2017; 2(13): 213-218.

10. Lyakh Yu. E. i dr. Osnovy komp yuternoj biostatistiki: analiz informaczii v biologii, mediczine i farmaczii statisticheskim paketom MedStat . Doneczk: Papakicza E. K.; 2006. 214. 